$\begin{array}{ll} & \text { Etnográfica } \\ \text { etnográfica } & \text { Revista do Centro em Rede de Investigação em }\end{array}$

Antropologia

vol. $17(2) \mid 2013$

Vol. $17(2)$

\title{
Turismo e sentido de lugar em óbidos: uma pousada como metáfora
}

Tourism and sense of place in Óbidos: a pousada-hotel as a metaphor

\section{Marta Lalanda Prista}

\section{(2) OpenEdition}

\section{Journals}

\section{Edição electrónica}

URL: https://journals.openedition.org/etnografica/3160

DOI: $10.4000 /$ etnografica. 3160

ISSN: 2182-2891

\section{Editora}

Centro em Rede de Investigação em Antropologia

\section{Edição impressa}

Data de publição: 1 junho 2013

Paginação: 369-392

ISSN: 0873-6561

\section{Refêrencia eletrónica}

Marta Lalanda Prista, «Turismo e sentido de lugar em Óbidos: uma pousada como metáfora», Etnográfica [Online], vol. 17 (2) | 2013, posto online no dia 20 junho 2013, consultado o 09 fevereiro 2022. URL: http://journals.openedition.org/etnografica/3160 ; DOl: https://doi.org/10.4000/ etnografica. 3160

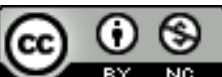

Etnográfica is licensed under a Creative Commons Attribution-NonCommercial 4.0 International License. 


\section{Turismo e sentido de lugar em Óbidos: uma pousada como metáfora}

\section{Marta Lalanda Prista}

Os estudos sobre o turismo tendem a centrar-se na mercadorização da cultura e nos encontros turísticos como práticas sociais que interagem com as economias e culturas dos destinos. Pesquisas realizadas na vila de Óbidos mostraram a necessidade de igualmente pensar o turismo na construção de um sentido de lugar. As perceções sociais sobre o património e o turismo fundem-se com as representações do passado em Óbidos. Esta construção é indissociável da constituição da cultura e história locais como enredo da produção do destino Óbidos, desde meados do século passado. Mas resulta também de um sentimento de exclusão social, hoje amplificado pela intensificação e profissionalização do turismo na vila. Perante novos atores e narrativas turísticas, uma parte significativa das populações de Óbidos convoca a autoridade de um património histórico e social e apropria-se dos discursos e práticas das elites como capital simbólico na construção do turismo como tradição local e prova da distinção cultural e social do lugar.

PALAVRAS-CHAVE: turismo, património, identidade, distinção, Pousadas de Portugal.

Tourism and sense of place in Óbidos: a pousada-hotel as a metaphor - Tourism studies tend to focus on tourism encounters and commoditization of culture as social practices interplaying with destinations' cultures and economies. A research carried out in the village of Óbidos showed the need to equally consider tourism in the construction of a sense of place. Heritage and tourism social perceptions intermix with representations of the past in Óbidos. This cannot be thought of outside the long-term production of local history and culture as the plots of Óbidos' tourism. But it also has to be examined in light of the social exclusion awareness, amplified by today's intensification and professionalization of the village's tourism. Confronted with new tourism' actors and narratives, a significant part of Óbidos' population invokes the authority of social and historical heritage, and embrace elites' representations and practices as a symbolic capital in the cultural and social distinction of place, and the construction of tourism as local tradition.

KEYWORDS: tourism, heritage, identity, distinction, Pousadas de Portugal.

PRISTA, Marta Lalanda (martaprista@gmail.com) - Centro em Rede de Investigação em Antropologia, Faculdade de Ciências Sociais e Humanas, Universidade Nova de Lisboa, Portugal. 
NÃO É POSSÍVEL PENSAR NA CONSTITUIÇÃO DO TURISMO COMO ÁREA de interesse científico sem remeter para o debate que a sua democratização estimulou, na década de $1970 .{ }^{1}$ Para as ciências sociais, os impactes do turismo nas culturas e comunidades de destino anunciavam novos terrenos e temas de reflexão. A distinção entre autenticidade e sua encenação para fins turísticos (MacCannell 1976) e a ideia de mercadorização da cultura como seu empacotamento e comercialização (Greenwood 1978) tornaram-se questões centrais. Estes conceitos foram estruturantes de vários estudos sobre as motivações, as atrações e os encontros turísticos (cf. Smith 1978). Um entendimento objetivista de autenticidade e mercadorização produziu visões negativas sobre a indústria turística como destruição das culturas locais e dos seus significados sociais, levando à conceção de formas alternativas de turismo (cf. Smith e Eadington 1992). Ao mesmo tempo, porém, a natureza dicotómica do par autenticidade/mercadorização esbateu-se, enquanto expressão das relações entre cultura e consumo que caracterizam a modernidade (cf. McCracken 1988). Novas reflexões repensaram a autenticidade como uma construção cultural e negociável que expressa valores, anseios e necessidades do mundo ocidental moderno (e.g. Cohen 1988). O turismo passou, então, a ser entendido como prática social inscrita em dinâmicas mais alargadas de identidade social e cultural (e.g. Butler 1992; Abram e Waldren 1997).

O que se pretende mostrar neste artigo, através da apresentação de uma pesquisa sobre a vila de Óbidos, é como o turismo pode incorporar um sentido de lugar. Os discursos das populações locais sobre Óbidos são narrativas que sublinham os impactes negativos do turismo no presente e naturalizam a sua produção no passado. Nesta construção, diferentes expressões, atores e tempos dos processos de mercadorização da cultura, ora confirmam uma identidade local, ora excluem o que está para além dela. Mais do que integrar as experiências sensoriais, simbólicas e afetivas que Tuan (1974) propõe serem produtoras do sentido de lugar, o turismo é uma prática social intrínseca aos modos como as populações de Óbidos vivem, conhecem, disputam, lembram e imaginam hoje a vila e, por isso, constituído e constituinte da experiência e representação do lugar (cf. Feld e Basso 1996).

As pesquisas realizadas na vila de Óbidos fizeram parte de uma investigação de doutoramento que procurou espacializar modalidades de representação e consumo do passado nas Pousadas de Portugal (Prista 201 1). ${ }^{2}$ A vila de Óbidos

l O meu agradecimento aos comentários e sugestões dos pareceristas da revista Etnográfica e à Fundação para a Ciência e a Tecnologia, entidade financiadora dos meus projetos de doutoramento (SFRH/BD/27556/2006) e de pós-doutoramento (SFRH/BPD/75978/2011).

2 Inauguradas pelo Estado Novo português em 1942, as Pousadas de Portugal são uma rede hoteleira de propriedade estatal com cerca de meia centena de estabelecimentos, maioritariamente instalados em edifícios de valor patrimonial e localizados em espaço rural. A rede anuncia-se como rota pelas tradições e história nacionais e experiência da hospitalidade e gastronomia portuguesas. 
e a Pousada do Castelo foram o primeiro terreno trabalhado por instrumentos de análise espacial e por métodos etnográficos, incluindo a realização de cerca de 85 entrevistas e conversas informais com atores sociais representativos dos habitantes, dos agentes políticos e turísticos e dos turistas locais. A seleção deste estudo de caso baseou-se na notoriedade da Pousada do Castelo na rede Pousadas $^{3}$ e ganhou consistência na expressão quase caricatural que a vila de Óbidos exibe dos processos de turistificação dos núcleos históricos patrimonializados, que têm centrado o trabalho de vários autores (e.g. Herzfeld 1991; Boissevain 1996a; Silva 2007, 2011). O que se observou ser invulgar, no caso de Óbidos, foi a fluidez encontrada nos entendimentos sociais de turismo, património e identidade, e a autoridade do passado e das elites nas representações das populações locais sobre o lugar.

\section{A VILA DE ÓBIDOS}

Até às Guerras Liberais (1828-1834), Óbidos era um termo extenso e uma vila cuja conquista por Afonso Henriques (1148) e integração na Casa das Rainhas (1210) associaram à fundação da nação (Trindade 2001). Leal à causa miguelista, Óbidos entraria então em declínio. No início do século XX, o concelho já só possuía nove das 37 freguesias anteriores, as atividades piscatória, agroflorestal e industrial eram deficitárias e a sua sede era pobre e densamente povoada (GTL s/d.). A situação contrastava, porém, com o crescimento económico e social da região do Oeste. O prolongamento da linha de caminho de ferro até às Caldas da Rainha (1888) impulsionou a indústria turística balnear e termal da região e a produção frutícola e vinícola de abastecimento à capital (Trigo 2004). Este desenvolvimento animou outras atividades económicas e culturais, levando ao protagonismo crescente de vilas como Torres Vedras, Peniche ou Caldas.

Inspirada pelo quadro regional, a autarquia de Óbidos procurou ultrapassar o declínio simbólico e económico do concelho solicitando ao poder central a restituição de terras perdidas (1897), a criação de banhos termais (1874) e a construção de uma estação de comboios (1907). ${ }^{4}$ Só em 1928, no entanto, Óbidos ensaiou um caminho para o desenvolvimento local, com a classificação da vila como estância turística e as primeiras iniciativas de promoção do destino. ${ }^{5} \mathrm{O}$ arcaísmo das estruturas urbana e social da vila e a sua localização

3 A Pousada do Castelo foi a primeira pousada instalada num monumento histórico, dando início ao segmento Pousadas Históricas, e é o único estabelecimento com taxas de ocupação superiores a 90\% durante todo o ano, possuindo nove quartos e não dispondo de equipamentos de lazer.

4 Atas da Vereação, Arquivo Municipal de Óbidos.

5 Entre estas iniciativas conta-se a publicação do Guia do Visitante (1929), a inauguração do Museu Regional (1930), a edificação de um Padrão Camoniano (1932), a taxa de turismo (1938), cobrada anualmente aos estabelecimentos de venda de bebidas (Ganhão 2009). 
privilegiada entre Lisboa e as Caldas da Rainha, a caminho dos mosteiros de Alcobaça e da Batalha, serviam um Estado que institucionalizara o turismo em 1911 e encontrava no valor romântico dos monumentos históricos um modo de celebrar o passado e a identidade da nação (cf. Tomé 2002). Foi neste contexto que o ulterior presidente da autarquia, Albino de Castro, propôs a classificação de toda a vila como património e destino nacionais, convocando a autoridade de autores como Ramalho Ortigão e Raul Proença na publicação dos seus ensaios e relatos de viagem a Óbidos (Castro 1933). ${ }^{6}$ A história monumental tornou-se, então, central ao projeto turístico de Óbidos. A vila foi palco das campanhas de restauro da Direcção-Geral dos Edifícios e Monumentos Nacionais (DGEMN) e em 1951 o núcleo muralhado foi homologado património. ${ }^{7}$ Procurando erguer testemunhos icónicos da nação, a DGEMN restaurou o castelo, as muralhas e vários edifícios religiosos e nobres, repondo a verdade histórica do nacionalismo oficial, ao anular elementos dissonantes dos tempos da fundação e glória da nação e reinventar os seus depoimentos materiais (DGEMN 1952).

As campanhas da DGEMN em Óbidos foram acompanhadas pela autarquia local em intervenções de natureza diversa. Desde logo, no plano simbólico, o feriado municipal de 1 de maio foi alterado para 11 de janeiro, data da conquista da vila por Afonso Henriques. ${ }^{8}$ Mais consequente foi a renovação da imagem do lugar, assistida pela ação do Secretariado de Propaganda Nacional (SPN) na construção de uma paisagem rural pitoresca e folclórica, que pretendia doutrinar o país nos valores do nacionalismo oficial e via no turismo um veículo privilegiado para a encenação da identidade nacional (cf. Pires 2003). Óbidos foi mesmo o cenário eleito para testar as pousadas regionais enquanto espaços performativos da nação, tendo hospedado o protótipo da rede (Estalagem do Lidador, 1940) e a primeira unidade em monumento nacional (Pousada do Castelo, 1950).

Outras intervenções em Óbidos lembram a ação do SPN nas povoações candidatas ao título de Aldeia Mais Portuguesa de Portugal (cf. Alves 1997). $\mathrm{Na}$ produção de uma "vila pitoresca", a autarquia homologou um conjunto de medidas que condicionaram o quotidiano e a continuidade das populações rurais na vila, ao mesmo tempo que promoveram o destino turístico junto das elites nacionais (Ganhão 2009). ${ }^{9} \mathrm{O}$ resultado foi uma reconfiguração dos tecidos sociais de Óbidos, com a saída das famílias pobres e numerosas, o retorno

6 O castelo de Óbidos era monumento nacional desde 1910 (DG n. ${ }^{\circ}$ 136, de 23 de junho).

7 Decreto n. ${ }^{\circ} 38147$, de 5 de janeiro de 1951.

8 Atas da Vereação, 1938, Arquivo Municipal de Óbidos.

9 São exemplos a proibição de mendicidade (1962) e de animais dentro da vila (1964), a obrigatoriedade de caiação e conservação do edificado (1964), a transmissão de peça de teatro na RTP (1957) ou o documentário sobre a Semana Santa (1963), e os subsídios a jornais e revistas para divulgação do destino. 
das famílias nobres da região e a chegada de personalidades políticas e artísticas da cena nacional (cf. Silva 1998). De forma mais sazonal ou permanente, estes novos grupos estabeleceram-se na vila, penetrando nas estruturas económicas e sociais locais e tomando a Pousada do Castelo como espaço de socialização. A audiência prometida pela pousada encorajou ainda o aparecimento de novos tipos de estabelecimentos comerciais e, durante as décadas de 1950 a 1970, apareceram os primeiros restaurantes, bares, lojas e pensões orientados para o consumo turístico.

As intervenções no espaço urbano de Óbidos esmoreceram até meados dos anos 70, mas pouco se alteraram no que respeita às metodologias, instrumentos e práticas patrimoniais. ${ }^{10}$ Só com os anos 80 novos entendimentos e usos do património reforçaram a sua viabilidade como recurso económico e simbólico capaz de contrariar a desertificação e desruralização do lugar. Sob o mote "Vila Museu", a autarquia instalou equipamentos culturais em edifícios nobres, eliminou traços de modernidade no espaço urbano e promoveu festivais de arte e música erudita (Garcia 2001). ${ }^{11}$ Simultaneamente, a Câmara Municipal criou o Dia do Turista e apoiou iniciativas locais de produção artesanal e cultural, no sentido de promover a participação social na turistificação de Óbidos. ${ }^{12}$ A especulação económica gerada pelo desenvolvimento do turismo e as políticas municipais de habitação e património não foram, contudo, capazes de contrariar a desertificação e terciarização da vila. ${ }^{13}$ Em finais da década de 1980, os efeitos da turistificação de Óbidos eram claros na sua escolha para sede da Região de Turismo do Oeste (1987) e na criação da Associação de Defesa de Património do Concelho (1989). Óbidos consolidou-se como lugar de paragem de excursões turísticas e escolares e a afluência em massa de visitantes desencadeou movimentos de salvaguarda do património local. Foi nesta altura que a Câmara Municipal adotou a divisa "Casa das Rainhas" e reforçou a associação entre a vila, as elites e a história nacional na promoção do lugar.

O curso do turismo em Óbidos só se alterou, no entanto, com a mudança do poder autárquico em 2001. ${ }^{14}$ Lançando a marca "Óbidos Vivo", a câmara autonomizou a intervenção municipal no património e no turismo com a

10 Consultar www.monumentos.pt (ficha PT031012040050).

11 São exemplos o 1. ${ }^{\circ}$ Festival de Música Antiga (1982), a 1. ${ }^{a}$ Bienal Internacional de Artes de Óbidos (1987), a conversão da igreja de Santiago em auditório municipal (1989), a supressão das antenas de televisão e a substituição do alcatrão por calçada na vila intramuros (anos 90).

12 A Câmara Municipal apoiou as bandas e grupos corais do concelho, do que resultou a criação do grupo coral Alma Nova (1981), e patrocinou também a formação e promoção da produção cerâmica artesanal, juntamente com a Misericórdia de Óbidos (1998).

13 Não obstante, iniciativas autárquicas como o concurso para a Reabilitação da Cerca do Castelo (1992-1997) e o Plano Diretor Municipal (1996) pretendiam salvaguardar, tanto quanto dinamizar a vida social da vila.

14 A Câmara Municipal foi presidida pelo mesmo autarca socialista entre 1980 e 2001, ano em que foi eleito o atual presidente social-democrata. 
criação de empresas, gabinetes e postos de trabalho especializados. No âmbito do património, foram regulamentadas disposições urbanas e arquitetónicas, foi formada uma rede de investigação com vista à candidatura da vila a património classificado pela UNESCO, e o discurso sobre o passado medieval e quinhentista de Óbidos foi alargado a novos tempos e espaços do concelho. ${ }^{15}$ No plano do turismo, os investimentos multiplicaram-se sob a gestão da empresa municipal Óbidos Patrimonium, que ampliou a rede de auditórios, museus, galerias e monumentos visitáveis, e que promove hoje diferentes iniciativas de cariz cultural e recreativo.

A política atual da Câmara Municipal é explícita: o turismo deve ultrapassar a sombra do património e constituir-se benefício para todo o concelho (Faria 2007). A adesão do setor privado é indiscutível: quase todas as tascas e mercearias foram transformadas em snack-bares ou lojas de artesanato e muitas unidades habitacionais oferecem alojamento informal. Num tecido urbano composto por 163 edifícios intramuros, em 2007 existiam mais de 66 estabelecimentos orientados para o consumo turístico. ${ }^{16}$ Esta superabundância tem expressão nos indicadores turísticos da região: o concelho de Óbidos representa apenas $6,4 \%$ da área da região do Oeste, mas a sua rede de equipamentos hospeda um quarto do total de dormidas regionais (INE 2008).

A estratégia municipal para o desenvolvimento do concelho tem igualmente expressão nos seus indicadores urbanísticos. A cobertura infraestrutural do município é bem superior à média regional (INE 2008). No entanto, quase não existem equipamentos de comércio e serviços não turísticos dentro da vila muralhada - Óbidos é comparada a uma Loja do Cidadão pelos habitantes e funcionários locais. ${ }^{17}$ Esta especialização funcional teve consequências sociodemográficas na vila. Entre 1940 e 2001, a população intramuros passou de 734 para 154 habitantes, 20\% dos quais eram sazonais. O contraste entre os dois grupos era notório: uma população permanente maioritária, com elevados índices de envelhecimento, de analfabetismo e de inatividade, coexistia com um grupo de residentes temporários com habilitações superiores e empregos qualificados em outros concelhos (INE 2001; GTL s/d.).

\section{UMA POUSADA COMO METÁFORA}

"A Pousada de Óbidos teve uma importância tão grande para o desenvolvimento destes conceitos todos [...] em Óbidos como a Torre Eiffel tem para Paris. Quer dizer, é uma referência e é uma âncora" (entrevista com representante da

15 As publicações mais recentes da Câmara Municipal abrangem temas tão diversos quanto as invasões francesas, a cidade romana de Eburobrittium, e a vida piscatória da Lagoa de Óbidos.

16 Estes números são resultantes do levantamento realizado durante o trabalho de campo.

17 Em 2007, havia uma caixa multibanco, uma agência de seguros e uma mercearia dentro da vila. 
Óbidos Patrimonium, 7 de agosto de 2007). Falando com as populações locais de Óbidos, ${ }^{18}$ compreende-se que o turismo não só é prática e representação que prevalece em discursos sobre o quotidiano da vila hoje, como informa e é informado por narrativas sobre o passado e a identidade do lugar. Sobretudo na leitura que fazem da história recente de Óbidos, as populações da vila verbalizam um consenso excecional relativo aos dois momentos que consideram balizar o desenvolvimento económico e social local: a construção do destino Óbidos, assinalada pela inauguração da Pousada do Castelo em 1950, e a transformação recente do projeto turístico da vila, atribuída à nova gestão do município (2001) e à nova gestão das Pousadas de Portugal (2003).

O primeiro momento traduz a ascendência da Pousada do Castelo sobre as representações do lugar. A inauguração da pousada marcou aquilo a que Prats (1997) chamou ativação do património - i.e., a produção de uma narrativa discursiva e material sobre o passado, cujas dimensões utilitárias, políticas e económicas reforçam a coesão social, a autoridade política e a viabilidade turística de um lugar. Por um lado, a pousada testemunha a produção de Óbidos como património nacional. Seguindo os princípios ideológicos da DGEMN, o restauro do castelo de Óbidos apoiou-se numa dupla aceção da ideia de restauração: o restauro material e o ressurgimento moral da nação (Tomé 2002). Não se tratava apenas de reerguer um ícone do passado histórico, mas de concertar ações nos planos material e social que, tomando a tradição como "uma lição de história" (Melo 2001: 47), garantissem a nacionalização da vida portuguesa (DGEMN 1952). Ecoando esta produção no presente, as populações de Óbidos descrevem o lugar como depoimento de um passado que é tão monumental quanto popular. Por outro lado, a pousada personifica a promessa cumprida de desenvolvimento local. A sua inauguração animou o projeto turístico lançado no fim da década de 1920 e fomentou o empreendedorismo numa economia fragilizada pelo fecho das fábricas da região e pelas dificuldades da atividade agropecuária. Além do mais, gerida e consumida por elites políticas e artísticas, a pousada tornou-se um capital simbólico local que atesta o valor cultural e social da vila, do seu património e dos seus habitantes.

É neste sentido que a Pousada do Castelo pode ser entendida como uma metáfora do lugar de Óbidos, constituindo um fragmento cuja exibição representa valores e significados da totalidade. Afinal, segundo Gonçalves (1996), o património é um recurso dramático necessário à ilustração de uma narrativa de identidade porque o acesso ao passado só é possível na representação, exibição e contemplação dos seus legados. Em Óbidos, aliás, não só a ativação patrimonial do Estado Novo encontra ressonância social hoje, mas lugar e pousada são atualizados como património coletivo,

18 Por populações locais entendem-se os habitantes intramuros e os antigos moradores ou residentes extramuros com relações quotidianas com o núcleo histórico. 
ao inscreverem-se em retóricas de perda que exprimem um desejo de resgate do passado e um sentido de propriedade. Esta retórica esclarece porque o segundo momento da história recente de Óbidos é localizado na mudança do poder autárquico (2001) e na privatização da gestão da rede Pousadas de Portugal (2003). Com tristeza, as populações locais consideram que a vila deixou de precisar da pousada e que a pousada se dissociou das estruturas económicas, políticas e sociais locais. Além de histórica, a afinidade entre ambas é agora reduzida à sua expressão material e territorial - a pousada está instalada no castelo cuja muralha define o lugar. Por detrás desta dissociação estão leituras sobre as recentes transformações em Óbidos que lembram os conceitos de "geografia recreativa" de Kirshenblatt-Gimblett (1998) e "economia cultural" de Dicks (2003).

A gestão privada das pousadas é acusada de quebrar os vínculos entre o estabelecimento e a vila por via de políticas de racionalização e centralização de recursos que se traduziram no outsourcing de serviços e bens e na profissionalização das equipas. Ao mesmo tempo, a renovação de menus e decoração e as novas campanhas de marketing reificaram a história como imagem da pousada, preterindo a sua identificação com a tradição da "vila pitoresca". Para a maioria das populações locais, a unidade do Castelo tornou-se parte de um itinerário de pousadas - uma espécie de "geografia recreativa" nacional, onde os clientes da rede podem apreciar a história e a tradição do país sem o constrangimento das realidades físicas e sociais dos seus lugares (cf. Kirshenblatt-Gimblett 1998). Simultaneamente, a intensidade turística desencadeada pelas políticas da nova gestão autárquica de Óbidos é associada à banalização do destino. O estabelecimento de uma "economia cultural" (Dicks 2003), enquanto estratégia de exibição inteligível e consumível da cultura para fins cognitivos e recreativos, não é em si contestado. O que a maioria da população rejeita é a sobreposição dos benefícios económicos e municipais aos interesses culturais e sociais locais.

Assumindo "vender Óbidos como uma marca", com retorno para todo o concelho, a autarquia aposta na cultura e na recreação como produtos compatíveis e concomitantes. Trata-se de uma atualização da indústria turística que responde ao entendimento contemporâneo da cultura como recurso, produto e experiência capazes de melhorar a competitividade e diferenciação dos destinos (Craik 1997). Mas é contra esta constituição da cultura como enredo do turismo que uma parte significativa da população de Óbidos reage. Na sua perspetiva, o turismo de hoje contraria a sua tradição como prática e interação sociais em harmonia com as estruturas físicas, sociais, culturais e económicas locais. O que está em causa é, assim, um entendimento do lugar constituído e constitutivo das inter-relações entre as atividades humanas e o espaço no tempo, confirmando a importância que lhe confere Tim Ingold (1993) na conceptualização da paisagem. Porque estas atividades não são distintamente técnicas 


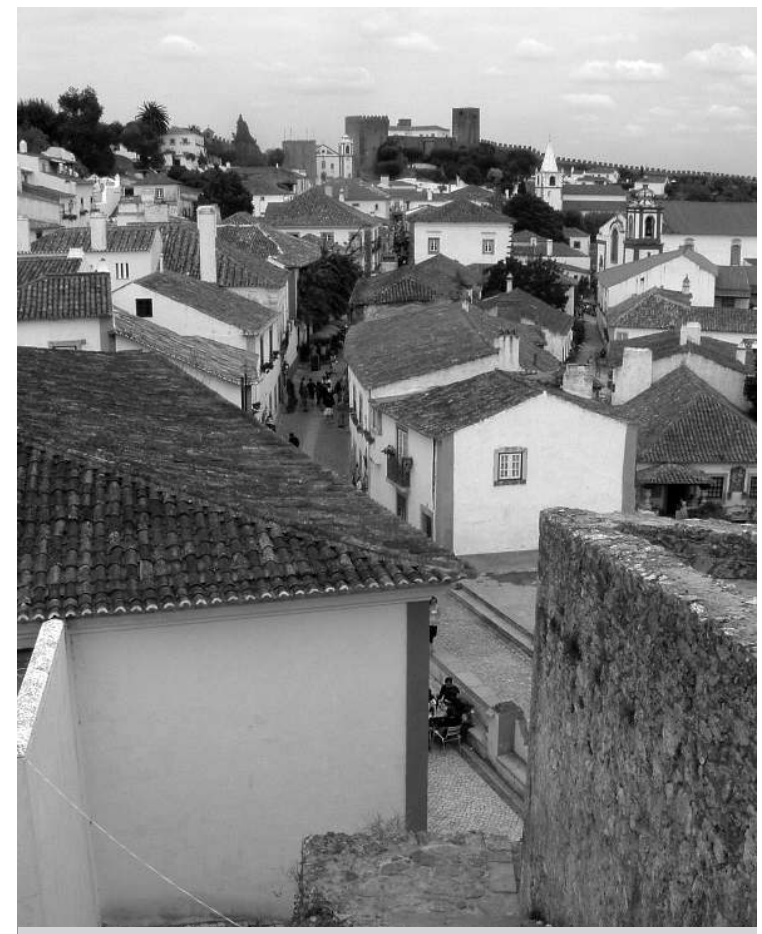

Figura 1 - Duas perspetivas sobre a rua Direita da vila de Óbidos. Fotografia de Marta Prista, 2007.

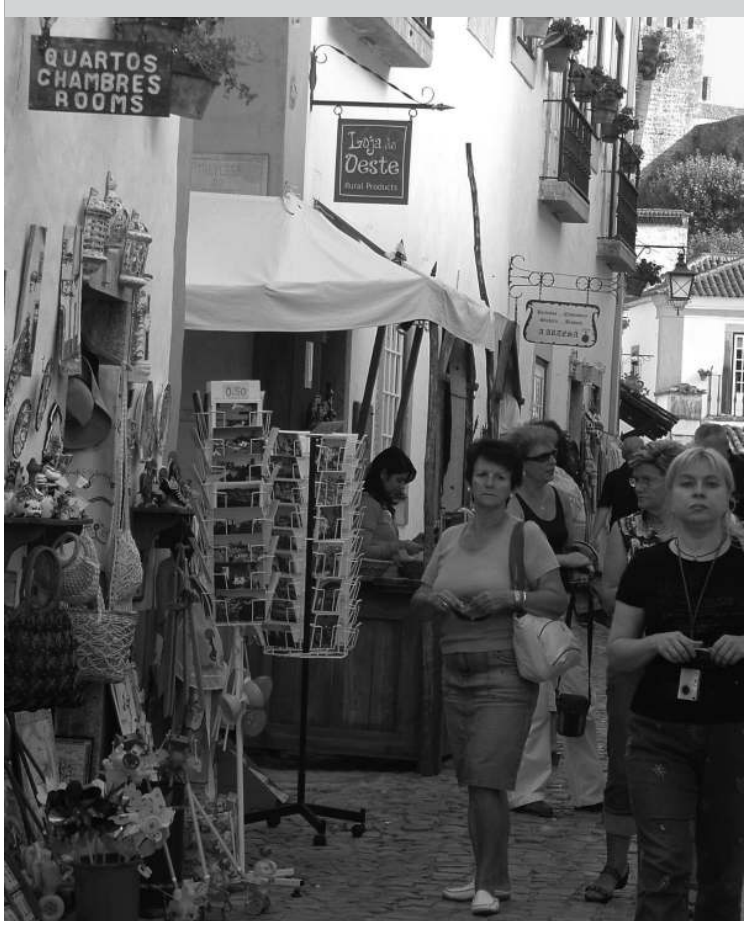


ou sociais, os novos atores turísticos de Óbidos representam uma ameaça à continuidade da experiência e representação sociais de um turismo "natural" local. Esta perceção é particularmente explícita na leitura que a maioria da população faz dos turistas, comerciantes, trabalhadores pendulares, e agentes políticos da intervenção turística e patrimonial.

\section{PERCEÇÕES SOCIAIS SOBRE OS ATORES LOCAIS DO TURISMO}

De uma forma geral, o turista de Óbidos é representado em função do seu alojamento ou passagem pela vila. Não se trata de uma distinção invulgar, tendo Luís Silva (2007) observado construções semelhantes em Sortelha e Monsaraz. No entanto, em Óbidos, a maioria das populações tende a polarizar esta distinção em visitantes da vila e hóspedes da pousada, descartando a presença de outros tipos de turistas e demarcando uma distinção social entre os dois grupos que retrata estereótipos identificados pelos estudos do turismo.

Os visitantes de Óbidos podem ser munícipes, excursionistas ou passantes e são entendidos como turistas sem capacidade económica, nem interesse cultural. A sua associação ao ruído e lixo produzidos, à indiferença perante o lugar e seus habitantes, e a comportamentos inadequados aproxima-os da ideia de turista de massas (cf. Smith e Eadington 1992). São pessoas que "vêm a Óbidos porque é moda", "estão mal informadas, não sabem o que é que vêm ver, veem o castelo e ficam impressionadas, bebem meia dúzia de copos de vinho e pronto, está feito”. Já os hóspedes da Pousada do Castelo são "pessoas selecionadas", "de qualidade", "que vinham cá almoçar e jantar por causa de a pousada ser o que era”. As populações comprovam o seu estatuto social elevado no apreço que manifestam pelo lugar, no distanciamento que mantêm face a atividades recreativas e nos seus consumos culturalmente informados e socialmente distintivos. É evidente uma negação da condição de turista aos hóspedes da pousada, que lembra a ideia de "antiturista" de Jacobsen (2000).

Esta representação polarizada dos indivíduos que visitam Óbidos ilustra os preconceitos de classe que Butler (1992) considera envolverem os estereótipos e as práticas turísticas e não é abalada pela emergência ou conceptualização de novas formas de turismo na vila. Uma munícipe chegou mesmo a afirmar que "esta história do turismo cultural tem muito que se lhe diga, é mais um produto de consumo”. Abram e Waldren (1997) advertem, porém, que é preciso repensar os encontros entre populações e turistas para além das primeiras propostas de Hosts \& Guests (Smith 1978). Para as autoras, o turismo fornece uma audiência externa para a performance de identidades ao realçar a distinção entre ser e não ser do lugar, ao marcar a diferença e exclusão que produzem uma identidade. 
Naturalmente, nem todos os turistas de Óbidos são visitantes da vila ou hóspedes da Pousada do Castelo, ${ }^{19}$ e nem toda a população entrevistada expressa de forma igualmente vigorosa a sua distinção social. O que se observou foi que esta distinção entre visitantes e hóspedes da pousada verbalizava menos uma leitura sobre o presente de Óbidos e mais uma construção idealizada do seu passado. Ora, segundo Hirsch (1995), é precisamente na mútua implicação entre a vida social quotidiana e a sua representação e idealização que deve ser analisada a paisagem enquanto processo cultural. Neste sentido, o regate de um turismo imaginado pelas populações de Óbidos pode ser entendido como expressão de uma resistência social ao quotidiano marcado pelas transformações recentes na gestão do município e da pousada. Por um lado, a intensificação da procura turística de Óbidos fragilizou o equilíbrio entre habitantes e visitantes ao sufocar a vida social local. Por outro lado, a privatização da gestão das pousadas conduziu ao aparecimento de um novo tipo de clientes, vistos como indivíduos sem capitais culturais e económicos significativos e, logo, distintos da ideia de hóspede. Esta é, aliás, uma perceção comum a outras vilas onde se desenvolveu esta pesquisa sobre as Pousadas de Portugal - vilas de Sagres, Arraiolos e Santa Maria do Bouro (Prista 2011). Quer as populações locais, quer os clientes da rede tendem hoje a associar o consumo das pousadas às estratégias de mobilidade social das novas classes médias, revelando um entendimento das dinâmicas de distinção em práticas turísticas (cf. Munt 1994). A questão é que, em Óbidos, o alargamento do espetro social dos hóspedes da Pousada do Castelo enfraquece uma diferenciação que é essencial à forma como a maioria da população local vive, lembra e representa o turismo no lugar.

Ao mesmo tempo que lamentam a presença dos novos turistas de Óbidos, vários habitantes e ex-moradores consideram ainda que o turismo da vila deixou de ser uma arena de representação da história e tradição locais. Este sentimento é associado ao aumento substancial de indivíduos de fora de Óbidos no quotidiano da vila e à sua monopolização da rede de comércio e serviços, desde o início da década de 2000. É certo que a especulação turística em Óbidos e a fragilidade da economia local cedo geraram a fixação de populações de fora do concelho. Mas, nos últimos anos, a intensificação do turismo, a desertificação e o envelhecimento do tecido social local, e o desenvolvimento das redes de comunicação e transporte conduziram a uma forte presença pendular de indivíduos residentes nas Caldas da Rainha, em Peniche ou em Lisboa. Estes indivíduos ocupam a grande maioria dos postos de trabalho da vila e possuem muitos dos seus estabelecimentos. Ora, o emprego no turismo é uma performance cultural onde se agenciam representações de identidade. A comercialização da hospitalidade é, por isso, uma forma de reivindicação da autoridade 
cultural que permite às populações negociarem desigualdades sociais (Herzfeld 1991). Compreende-se, deste modo, porque parte da população de Óbidos se sente lesada pela presença deste grupo de atores sociais. Embora alguns habitantes relativizem os seus prejuízos, considerando que "o emprego é para os jovens e aqui não há jovens", outros sentem-se usurpados dos benefícios prometidos pelo turismo e, sobretudo, ignorados como autoridade na representação do lugar.

As tensões entre estes dois grupos sociais locais - de Óbidos e de fora de Óbidos - acentuam-se na Pousada do Castelo. A profissionalização dos recursos humanos pela nova gestão levou à diminuição do número de funcionários locais e ao aumento de profissionais habilitados vindos dos meios urbanos e até de outros países. Esta substituição gerou conflitos que foram agravados pelo valor local do emprego na pousada. De modo análogo à construção do capital social sobre os capitais familiares e escolares proposta por Bourdieu (2007 [1979]), os funcionários locais da pousada geriram a sua naturalidade e o valor profissionalizante do emprego nas Pousadas de Portugal como uma forma de distinção social. Além da autoridade na representação do lugar, é este capital que a nova política de recursos humanos das pousadas ameaça; um capital que ademais se estende ao exterior dos vínculos laborais, por força da longevidade e profundidade das relações entre a unidade do Castelo e as redes familiares e sociais locais.

A maioria das populações de Óbidos não se ressente apenas da preponderância dos novos atores sociais no turismo da vila, mas igualmente dos efeitos do seu controlo sobre a mercadorização de bens culturais. No passado, a promessa de uma audiência turística e a escassez da cultura material local justificou a venda de produtos de outras regiões e de artesãos-artistas recém-chegados. Como resultado, as mantas de Seia ou o cabrito assado são hoje entendidos como "artesanato português" e "cozinha tradicional", num processo de deslocalização e ressocialização das tradições regionais à escala nacional que não anula totalmente a sua autenticidade no lugar. Ao mesmo tempo, a latoaria pintada ou os bordados produzidos desde meados do século XX tornaram-se tradições locais por via da naturalidade ou naturalização dos seus artesãos. Com a terciarização da vila e a profissionalização do turismo, no entanto, novos produtos começaram a ser comercializados. São vistos como objetos "que não têm nada a ver com Óbidos", um conjunto de "chinesices" e de "modernices" introduzidas pelos novos intermediários culturais em resposta à popularização do consumo do passado (cf. de Groot 2009). ${ }^{20} \mathrm{O}$ desagrado das populações de Óbidos pela venda destes produtos depende dos benefícios conseguidos e da

20 São citados objetos tão diversos como as canecas alusivas aos clubes de futebol nacionais, as "roupas indianas", o merchandising da Câmara Municipal, ou as peças de design moderno fabricadas em cortiça. 
proximidade de cada indivíduo com a indústria turística. Mas, de uma forma geral, a sua comercialização é encarada como resposta economicista ao gosto de turistas que "não querem saber nada da história" de Óbidos, num entendimento que remete para a mercadorização da cultura como processo que conduz à destruição dos seus significados sociais (cf. Greenwood 1978).

Quer as representações sociais dos novos turistas de Óbidos, quer as perceções sociais das novas formas de mercadorização da hospitalidade e cultura local, apontam para uma recusa da modernização da indústria turística da vila por parte das populações e explicam o antagonismo dirigido à política municipal. Não rejeitando a aliança entre património e turismo que orienta a política turística em Óbidos desde a década de 1950, a Câmara Municipal atualizou porém os seus valores, produtos e estratégias. A história e a cultura são hoje recursos simbólicos e económicos capitalizados em políticas de desenvolvimento municipais que procuram restaurar o protagonismo de Óbidos na região e captar investimentos privados no município, não só revertendo na melhoria das condições de vida das populações, como servindo de exemplo a outros destinos nacionais (Faria 2003, 2007). Este entendimento dos usos da cultura levou à produção de novas atrações turísticas e de novas dimensões do património, estratégias comuns na resposta da indústria turística à competitividade dos destinos patrimoniais e culturais (cf. Timothy e Boyd 2003). Destas, os eventos são o tema que melhor ilustra os conflitos entre populações e autarquia sobre a imagem do turismo de Óbidos.

Para a Câmara Municipal, os eventos são um conjunto de festas, feiras e concertos que, diversificados na natureza e distribuídos ao longo do ano, alargam o público-alvo de Óbidos, combatem a sazonalidade do turismo e conferem viabilidade económica ao destino. Se os eventos culturais garantem o prestígio de Óbidos, os mais comerciais consolidam o orçamento do município. Acontece que as populações locais só reconhecem benefícios da estratégia para os comerciantes e munícipes. Aos habitantes da vila resta-lhes tolerar a afluência excessiva de visitantes e suportar os problemas decorrentes da desertificação e terciarização locais. Como afirmou um morador, "isto é um espetáculo que aqui existe. Nós somos os atores, mas depois não recebemos cachet".

O entendimento dos diferentes tipos de eventos pelas populações de Óbidos não é, contudo, homogéneo. Iniciativas como o Festival de Ópera ou a Semana Internacional de Piano (SIPO), apesar de não lucrativas, obtêm a sua aprovação. Já festivais como o Chocolate ou o Vila Natal são alvo de fortes críticas, não obstante originarem receitas municipais avultadas. Nenhum destes eventos versa sobre a grande narrativa histórica de Óbidos - o património medieval e todos constroem a vila como cenário. A mercadorização e esteticização da história em Óbidos parece, assim, ser aceite em função da consonância dos valores comercializados com a representação do lugar pelas populações locais. O Festival de Ópera e a SIPO, por exemplo, trazem uma audiência limitada 
e qualificada que não provoca incómodos ao quotidiano da vila e apela ao gosto pela alta cultura. Já o Festival do Chocolate e o Vila Natal ignoram o património histórico e chamam um número excessivo de visitantes indesejados, económica e socialmente. O mesmo tipo de turistas chega a Óbidos para o Mercado Medieval, mas este é uma dramatização moderna da história que retrata o mito de fundação da vila. As atitudes das populações de Óbidos face a esta iniciativa são por isso paradoxais. Embora acusado de "apalhaçar" a vila e condicionar o seu quotidiano, o enredo do Mercado Medieval desculpabiliza a sua especulação económica e a participação dos munícipes na sua produção satisfaz a memória e os anseios de uma atividade que envolva e beneficie as populações.

Em síntese, a cultura como enredo do turismo de Óbidos é oficialmente assumida e as populações locais não recusam as relações entre cultura e consumo na produção do destino. A natureza utilitária e económica destas relações é aceite e suporta e comunica categorias culturais e significados sociais. O que é socialmente contestado são os valores produzidos nos "momentos de transferência de significados" do mundo culturalmente construído para os bens de consumo, e destes para as representações e práticas dos consumidores (cf. McCracken 1988). De uma forma geral, as populações de Óbidos acusam os comerciantes e o município de reconfigurar o turismo local de modo a torná-lo apetecível ao gosto de um maior número de visitantes, assim conduzindo à desdiferenciação social e trivialização cultural do destino. Claro que o consumo não é uma dicotomia e não pode ser visto apenas como realização individual ou espelho das relações de dominação capitalista (Sassatelli 2007). Através do consumo, os indivíduos negoceiam valores simbólicos inscritos nos bens, mas também produzem significados culturais e configuram o espaço social. Neste sentido, as perceções sociais dos novos atores do turismo em Óbidos precisam de ser entendidas como parte de um quadro mais alargado de práticas e representações que envolvem as populações com o lugar.

\section{SENTIMENTOS DE EXCLUSÃO E ESCALAS DE PERTENÇA:}

A MURALHA E O CASTELO

Ouvindo as populações de Óbidos retratar os turistas da vila, contestar a mercadorização atual da cultura local e lamentar o caminho escolhido pela autarquia na produção do destino turístico, é notória a semelhança com outros núcleos históricos turistificados. Estes discursos revelam um sentimento social de exclusão dos interesses dos habitantes nas políticas patrimoniais, próximo do identificado em Rethemnos na Grécia (Herzfeld 1991) e em Castelo Rodrigo (Silva 2011), e na indústria turística, como observado em Mdina, na ilha de Malta (Boissevain 1996a), ou em Sortelha e Monsaraz (Silva 2007). No caso de Óbidos, trata-se de um sentimento de exclusão simultaneamente 
territorial, económica, cultural e social que ecoa os constrangimentos à habitação, à atividade económica e à interação social.

Este sentimento de exclusão configura, naturalmente, uma fronteira de inclusão. Os eventos turísticos de maior dimensão são particularmente ilustrativos. Na sua produção e consumo, residentes, antigos moradores e populações sazonais de Óbidos confrontam-se com outros munícipes, turistas e trabalhadores pendulares. Nestes encontros, cada grupo se redefine em relação aos restantes através de escalas de pertença local. Analisando a turistificação de festas locais em Naxxar (Malta), Boissevain (1996b) relativizou a destruição da cultura pela sua mercadorização, ao verificar o papel das festividades e das suas diferentes audiências na celebração de identidades e na reconfiguração das suas fronteiras. Negociações semelhantes parecem ocorrer em Óbidos, a muralha do castelo diferenciando duas escalas de construção do lugar - a vila e o município.

Como em Mdina, a vila de Óbidos tornou-se a corporização da história no concelho (cf. Boissevain 1996a). Trata-se de um património que consagrou ao concelho um lugar no mapa nacional e cuja mercadorização proporciona melhorias na qualidade de vida dos munícipes. Assim, ainda que estes não mantenham relações quotidianas com a vila, a fragmentação das várias identidades municipais foi diluída e, nas palavras de uma residente de outra freguesia, “as pessoas já não são de nenhuma das terras do concelho, são de Óbidos". Para habitantes intramuros, no entanto, os outros munícipes são tão visitantes como os excursionistas e os domingueiros. Esta associação sugere, inclusive, que os estigmas turísticos também servem de escape a outras tensões sociais, nomeadamente decorrentes da distribuição desigual dos benefícios e constrangimentos do turismo e das disputas na representação do lugar. A verdade é que, para os residentes e ex-moradores da vila de Óbidos, a identidade local é mais restrita e forma-se em torno de um sentimento de sacrifício das populações intramuros. Este sacrifício é legitimado pelo reconhecimento da autarquia, que atribui compensações aos moradores, mas a maioria destes considera tratar-se de regalias que pouco atenuam o esforço num investimento cujo retorno é municipal. ${ }^{21}$

O lugar do castelo e da muralha nos modos de espacialização das relações e práticas sociais das populações de Óbidos não é de desprezar. A muralha delimita simbólica e fisicamente as representações de identidade e o castelo é o seu signo. Mas, como Abram e Waldren (1997) ressalvam, as identidades revelam-se em ações, discursos e símbolos que as constituem, mais do que representam, e por isso o turismo não só fornece uma audiência para a performance cultural, como também encerra práticas que a produzem. É neste

21 Estas compensações traduzem-se, por exemplo, na oferta de bilhetes para eventos, ou na isenção do imposto municipal sobre imóveis. 
sentido que o uso de percursos alternativos e de espaços de socialização extramuros pelas populações da vila, ou o seu conhecimento dos recantos históricos de Óbidos e autoidentificação como "toupeiros" merecem atenção. ${ }^{22}$ Porque, aceitando a perspetiva fenomenológica, o lugar não é a inscrição cultural e social sobre o espaço absoluto, mas sim o conhecimento corporizado de uma perceção sinestética simultaneamente ativa e passiva, absorvida, constituída e constitutiva (cf. Casey 1996), estas práticas e discursos espaciais são manifestações de uma identidade objetificada num lugar que é representado à imagem de um passado recente e vivido à sombra da uma muralha medieval.

\section{DISCURSOS SOBRE O PASSADO: PATRIMÓNIO HISTÓRICO, ELITES E TURISMO}

O património não é espontâneo ou natural, antes resulta de uma construção cujo propósito é simbólico, utilitário e serve a identificação de um grupo social determinado no tempo e no espaço. Tem, por isso, uma natureza propositiva que não só o distingue da história, como lhe confere a capacidade de renovar o passado nos moldes desejados pelo presente (Lowenthal 1985). Numa pesquisa sobre a construção de uma tradição marítima em Ílhavo, Elsa Peralta (2010) sublinhou a necessidade de pensar a memória coletiva como entidade mediada por uma continuidade com o presente. A autora mostrou como a ideia de ilhavense foi essencializada, constituindo as populações locais em herdeiras de um passado reificado sobre a pesca do bacalhau e capitalizado pelo discurso político e turístico local. A história recente de Óbidos sugere um processo semelhante. Nesta vila, o turismo foi socialmente construído como tradição e atividade que suscitam o orgulho e o sacrifício das populações e têm consequências na organização e representação sociais dos obidenses. Como em Ílhavo, a atual apropriação da memória pelos atores políticos e turísticos locais é associada à sua trivialização. O problema é que, em Óbidos, a capitalização política e económica desta memória local opera na sua própria essência - o turismo.

Ora, o património expressa uma retórica de perda e é ativado face à ansiedade que esta cria relativamente ao futuro. Para as populações de Óbidos, o que está em causa é a continuidade de um modo de vida em íntima relação com o turismo local. O antagonismo social face aos novos atores turísticos - quem visita, representa e produz o destino Óbidos - parece, assim, expressão da construção de uma memória e passado locais que, tão factuais como

22 O termo "toupeiros" remete para a lealdade dos obidenses à vila. Assumindo um desconhecimento histórico preciso, vários indivíduos entrevistados se reportaram a um cerco à vila no período medieval, durante o qual os habitantes intramuros usaram túneis subterrâneos para se abastecer, sem nunca abandonar o lugar. 
ficcionados, recuam à ativação patrimonial do lugar pelo Estado Novo e são legitimados pela autoridade política, social e intelectual dos discursos e práticas das elites do passado e do presente.

Um dos aspetos que mais chama a atenção no discurso das populações de Óbidos sobre o lugar é a ressonância social dos processos de patrimonialização do espaço histórico da vila, quer monumental, quer doméstico. Trata-se de um património cujas dimensões simbólicas e económicas são centrais à construção do lugar, facto a que não são alheias a longevidade e a intensidade dos investimentos nacionais e locais em Óbidos. O que é curioso é que, embora a reinvenção do espaço físico seja reconhecida pelas populações da vila, tal não perturbe a representação de Óbidos como testemunha tangível da história e tradição nacionais. Algumas intervenções no espaço histórico chegam mesmo a ser zombadas como produções para enganar turistas, mas é transversal o orgulho das populações num património que consideram autêntico e de que se reveem proprietárias. Mesmo tradições como as cores dos cunhais ou as floreiras nas fachadas são lembradas como imposições do poder autoritário, mas hoje igualmente imprimem autenticidade ao lugar e a sua ausência é um comprovativo da exclusão social das populações locais.

Não é que não haja em Óbidos um descontentamento com as disposições regulamentares sobre o património, com o favorecimento ou a arbitrariedade das suas permissões, tal como acontece em outros lugares (e.g. Silva 2011). Mas, de uma forma geral, as contestações aos imperativos patrimoniais cingem-se aos condicionamentos à habitabilidade do espaço interior privado. Há uma distinção social entre conservação histórica e conservação da antiguidade, como Herzfeld (1991) observou em Rethemnos. O que não há é uma dissociação entre património monumental e património social. A maioria das populações recusa a produção da vila como palco de uma história estática e objetificável que serve de cenário às práticas turísticas, e considera que "o património somos nós, nós é que o fazemos, nós é que vivemos a vila". Dão, assim, expressão social à distinção conceptual entre uma "paisagem de memória", que toma o espaço como superfície de inscrição e codificação de significados, e uma paisagem como processo cultural, social e dinâmico, constituído por atos de rememoração e de esquecimento, dos quais é igualmente um produto (cf. Küchler 1993). Comparando o porvir da vila a um "museu ao ar livre" ou "uma espécie de Disneylândia", estas populações mostram receio do seu apagamento como "património vivo" de um lugar concebido na intimidade do turismo com as estruturas físicas, económicas, culturais e sociais.

Esta construção social de um "património vivo" em Óbidos contesta o significado que lhe dá hoje o município - os turistas como vida de um lugar patrimonializado - e ecoa outros discursos sobre o passado e o turismo locais. Naturalmente, trata-se de uma apropriação fragmentada em função dos interesses e representações sociais do presente, e não são ausentes ambiguidades 
e contradições. A ideia de vila como património, por exemplo, atualiza a classificação de 1951 e a conceção da aldeia pitoresca e histórica. O monumento Óbidos é agora entendido como espaço simultaneamente material e social, explicando a equivalência simbólica da história monumental e popular, das elites aristocráticas e das famílias rurais, na construção da antiguidade e identidade do lugar. A ressonância social, ainda que parcial, da retórica do Estado Novo é algo paradoxal, na medida em que confirma o valor cultural de Óbidos, mas a subsequente reconfiguração dos tecidos sociais locais é tanto um capital, como uma ameaça à continuidade social na vila.

Outros discursos mais eruditos que políticos são ativados pelos depoimentos das populações de Óbidos sobre os prejuízos sociais e simbólicos da turistificação da vila, em especial pelos segmentos que desta não beneficiam diretamente. A profissionalização dos serviços municipais de turismo e de cultura levou à presença diária de um novo grupo social, constituído por indivíduos com competências técnicas e científicas para se pronunciarem sobre a cultura e a história do lugar. Como verificaram Boissevain e Theuma (1998) a propósito do planeamento urbano em Malta, o desempenho social da autoridade disciplinar destes intermediários culturais condiciona e inspira as narrativas das populações sobre os seus lugares. Em Óbidos, estas elites intelectuais detêm, assumem e exercitam um conhecimento sobre a vila que tem vindo a ser apropriado nos discursos sobre a história local, na denúncia de invenções da tradição e na renovação de traços de identidade. Trata-se sempre de uma apropriação seletiva e conflitual, já que mediada por interesses de populações que tanto procuram legitimar o seu sentimento de exclusão, como confirmar a natureza dos vínculos entre lugar e turismo. Assim, as atuais revisões da história de Óbidos que invocam o passado maneirista ou industrial do lugar são preteridas a favor de narrativas sociais que privilegiam a imagem de aldeia medieval. Mas a contestação erudita à ideia de uma vila em decadência, no início do século XX, e a sua equiparação com a vida rural nacional, serve a construção social do lugar como vila tradicional de Portugal.

As elites não são, porém, apenas autoridades narrativas e disciplinares que legitimam as representações sociais do passado de Óbidos. Desde a publicação de Albino de Castro em 1933 que as elites aristocráticas e românticas são igualmente um capital simbólico do destino Óbidos. A posterior inauguração da Pousada do Castelo não foi inocente, nem inconsequente. A adaptação do paço quinhentista a pousada, a sua decoração como "confortável moradia dum grande senhor feudal" 23 e a concessão da gestão à atriz italiana Luísa Santanela sugerem ter havido um investimento nos laços históricos entre património e elites como valorização social do lugar. As transformações demográficas 
posteriores à década de 1950 confirmaram o seu sucesso, com o estabelecimento permanente ou temporário de indivíduos da esfera política e artística da capital e de antigas famílias endinheiradas da região.

O capital social das elites manteve-se um valor turístico na promoção de Óbidos, especialmente quando a intensificação da sua procura levou a autarquia a delinear estratégias de diferenciação do lugar, no final da década de 1980. Este investimento simbólico extravasou, inclusive, as esferas políticas e turísticas. Reis e rainhas, elites românticas, personalidades da vida política e artística do Estado Novo e hóspedes da Pousada do Castelo tornaram-se também um capital simbólico gerido a diferentes escalas de identificação pelas populações de Óbidos. Por um lado, as elites constituíram a vila num objeto de gosto, uma marca da classe, ao deterem o gosto legítimo e confirmarem e atualizarem a sua distinção social em práticas de consumo, como as turísticas (cf. Bourdieu (2007 [1979]). Esta identificação do lugar com o gosto das elites tem vindo a suportar a diferenciação cultural de Óbidos e a autenticar o valor do seu "património vivo". Por outro lado, as elites são um capital simbólico agenciado em estratégias de mobilidade social por vários habitantes e ex-moradores da vila que hoje reivindicam relações profissionais, sociais ou familiares com o alcaide, Luísa Santanela, Albino de Castro ou antigos hóspedes da Pousada do Castelo.

Como verificou Sobral (2004) numa vila das Beiras, a história das elites pode ser mais que uma expressão de dominação simbólica nas esferas administrativas, económicas ou sociais. É por isso que, em Óbidos, a elitização do Castelo não foi, nem é, contestada, contrariando a tendência para os conflitos sociais em espaços que, apropriados pelas elites, excluíram deles as suas populações (cf. Low e Lawrence-Zúñiga 2003). Se há algum movimento de ressocialização destes visitantes, ele é no sentido da sua naturalização. Parte destas elites associou-se à produção do destino, adquirindo e restaurando propriedades, investindo como consumidores e promotores da atividade turística local. São indivíduos vistos como pessoas com verdadeiro interesse na história, na cultura e no desenvolvimento do lugar e, por isso, "praticamente de Óbidos". É assim que as elites de Óbidos são simultaneamente uma audiência e um grupo social local.

Este processo de naturalização das elites em Óbidos teve visibilidade na produção de atrações turísticas e na construção de algumas das práticas sociais e culturais como expressão de autenticidade e tradição locais. A instalação do Museu Municipal na anterior residência do pintor Eduardo Malta ou a abertura da Casa Museu Abílio Mattos Silva ilustram os investimentos políticos no prestígio das elites como reforço da autoridade cultural no lugar. A revalorização da Semana Santa como celebração que atraía visitantes ilustres a Óbidos produziu uma nova dimensão da tradição local. No conjunto, são iniciativas que confirmam o duplo papel das elites na construção do lugar. 
Este processo de ressocialização de indivíduos, práticas e discursos do passado não é insólito e, em Portugal, vários investimentos patrimoniais recuam às construções culturais e etnográficas do Estado Novo (e.g. Alves 1997; Peralta 2010). O que se observou em Óbidos foi que a representação social das expressões da cultura local depende geralmente do capital social dos produtores, atores e consumidores envolvidos na sua mercadorização. Vários exemplos poderiam ser citados, o caso da ginja é esclarecedor. A sua comercialização pelo senhor Montez que, vindo de Santarém, abriu uma loja de antiguidades e o primeiro bar da vila para o consumo dos primeiros visitantes de Óbidos - os hóspedes da pousada - enraizou-se como expressão da hospitalidade local. Mas a venda da ginja em copos de chocolate pelos comerciantes da vila, associada ao festival internacional que ali decorre anualmente, remete para um turismo indesejado e é denunciada como subversão de uma tradição local.

\section{NOTAS FINAIS}

A relação entre cultura e consumo na produção e construção social de Óbidos é um traço sólido e constante na sua história recente. Não é, por isso, surpreendente a proximidade das representações de turismo, património e identidade nos discursos das populações de Óbidos sobre o seu lugar. Segundo Abram e Waldren (1997), o sentido de lugar é produzido nas relações com o Outro e o turismo fornece, de modo particular, uma audiência externa com a qual se estabelecem trocas dinâmicas que formatam e produzem significados e valores de identidade. A identidade é, todavia, um discurso produzido e produtor da marcação de diferença, pelo que as suas expressões culturais e práticas sociais são tão constitutivas quanto representações dessa identidade. É neste sentido que melhor se pode entender a construção do turismo em Óbidos como tradição local e o sentimento de exclusão de parte das populações como obstáculo à performance de uma identidade.

A propósito da patrimonialização de um núcleo histórico habitado e turistificado, Herzfeld (1991) mostrou como o poder político, os especialistas e as populações disputam a propriedade sobre o passado em discursos e práticas que opõem narrativas monumentais e sociais sobre a história. Em Óbidos, esta dissonância entre tempo social e tempo monumental tem de ser relativizada. As populações locais não se debatem por uma redefinição da história. Pelo contrário, o tempo social é, se possível, mais monumental do que a narrativa oficial. A vila medieval e pitoresca produzida pelo Estado Novo ecoa hoje na construção social do lugar de Óbidos, tal como as práticas e atores associados à abertura da Pousada do Castelo corroboram o turismo como tradição local. As populações reativam os laços entre património e elites e revelam uma amnésia parcial quanto a traços culturais e modos de vida que não os envolvam no passado de Óbidos. 
Craik (1997) afirma que a cultura do turismo moderna se estrutura sobre a simultânea modelação da cultura pelo turismo e vice-versa. Esta dinâmica é irrefutável em Óbidos, mas não é entendida de forma idêntica por populações locais e por atores políticos e turísticos. Sem prejuízo das revisões críticas posteriores, os termos "autenticidade encenada" (MacCannell 1976) e "autenticidade emergente” (Cohen 1988) clarificam esta distinção. Desde meados do século XX que a produção turística do destino Óbidos encena a história e as tradições locais em função das ideologias políticas e dos anseios turísticos. Esta turistificação tem vindo a ser atualizada e hoje rege-se pelos princípios de profissionalização e democratização da indústria global. Como resultado, os encontros turísticos alteraram-se, afastando e abafando uma vida social local em inferioridade numérica face a turistas e outros atores sociais não locais. É neste contexto que o passado recente de Óbidos é resgatado e as narrativas, práticas e atores turísticos de outrora são imaginados e recordados como um modo de vida local que identifica simbólica e emocionalmente as indivíduos com o lugar. Mas é também à sua sombra que as populações de Óbidos vivem, percecionam, contestam e investem significados no lugar hoje, conferindo-lhe um sentido (cf. Feld e Basso 1996). Este sentido de lugar precisa, por isso, de ser entendido como objectificação de um processo cultural constituído e constituinte das relações entre o quotidiano social e a potencialidade da sua representação (cf. Hirsch 1995), o que em Óbidos remete para entendimentos imbricados de turismo, património e identidade.

\section{BIBLIOGRAFIA}

ABRAM, Simone, e Jacqueline WALDREN, 1997, "Introduction", em Simone Abram, Jacqueline Waldren e Donald Macleod (orgs.), Tourists and Tourism: Identifying with People and Places. Oxford e Nova Iorque, Berg Publishers, 1-11.

ALVES, Vera Marques, 1997, "Os etnógrafos locais e o Secretariado da Propaganda Nacional: um estudo de caso”, Etnográfica, I (2): 237-257.

BOISSEVAIN, Jeremy, 1996a, “'But we live here!': perspectives on cultural tourism in Malta”, em Lino Briguglio et al. (orgs.), Sustainable Tourism in Islands and Small States: Case Studies. Londres, Pinter, 220-240.

BOISSEVAIN, Jeremy, 1996b, "Ritual, tourism and cultural commoditization: culture by the Pound?", em Tom Selwyn (org.), The Tourist Image: Myths and Myth Making in Tourism. Londres, John Wiley \& Sons, 105-120.

BOISSEVAIN, Jeremy, e Nadia THEUMA, 1998, “Contested space: planners, tourists, developers and environmentalists in Malta”, em Simone Abram e Jacqueline Waldren (orgs.), Anthropological Perspectives on Local Development. Londres, Routledge, 96-1 19. 
BOURDIEU, Pierre, 2007 [1979], A Distinção: Crítica Social do Julgamento. São Paulo, Edusp; Porto Alegre, Editora Zouk.

BUTLER, Richard, 1992, "Alternative tourism: the thin edge of the wedge", em Valene Smith e William Eadington (orgs.), Tourism Alternatives. Filadélfia, University of Pennsylvania Press, 31-46.

CASEY, Edward, 1996, "How to get from space to place in a fairly short stretch of time", em Steven Feld e Keith Basso (orgs.), Senses of Place. Santa Fe, School of American Research Press, 13-52.

CASTRO, Albino de (org.), 1933, Turismo, Óbidos: Impressões de Vários Homens Notáveis após a Visita a Este Velho Burgo. Marco de Canavezes, s/ed.

COHEN, Erik, 1988, "Authenticity and commoditization in tourism", Annals of Tourism Research, 15 (3): 371-386.

CRAIK, Jennifer, 1997, “The culture of tourism”, em Chris Rojek e John Urry (orgs.), Touring Cultures: Transformations of Travel and Theory. Londres, Routledge, 113-136.

DE GROOT, Jerome, 2009, Consuming History: Historians and Heritage in Contemporary Popular Culture. Oxon, Routledge.

DGEMN, 1952, "Castelo de Óbidos", Boletim da Direç̧ão-Geral dos Edifícios e Monumentos Nacionais, 68-69. Lisboa, MOP.

DICKS, Bella, 2003, Culture on Display: The Production of Contemporary Visitability. Londres, Open University Press.

FARIA, Telmo, 2003, “Entrevista no Semanário Expresso: Maria João Avillez conversa com Telmo Daniel Faria”, RIO - Revista Informativa de Óbidos, 1 (7): 14-17.

FARIA, Telmo, 2007, "Editorial: discurso feriado municipal 2007", RIO - Revista Informativa de Óbidos, 3 (36): 3-5.

FELD, Steven, e Keith BASSO, 1996, “Introduction”, em Steven Feld e Keith Basso (orgs.), Senses of Place. Santa Fe, School of American Research Press, 3-11.

GANHÃO, Paula, 2009, O Turismo em Óbidos durante o Estado Novo: Narrativas Turísticas Inspiradas na Política de Espírito: dos Anos 20 aos Anos 70. Lisboa, ISCTE, tese de mestrado.

GARCIA, Luís Manuel, 2001, Óbidos: 20 Anos de Intervenção Autárquica: 1980-2000. Óbidos, Câmara Municipal de Óbidos.

GONÇALVES, José Reginaldo dos Santos, 1996, A Retórica da Perda: Os Discursos do Património Cultural no Brasil. Rio de Janeiro, Editora UFRJ.

GREENWOOD, Davydd, 1978, "Culture by the pound: an anthropological perspective on tourism as cultural commoditization", em Valene Smith (org.) Hosts and Guests: The Anthropology of Tourism. Oxford, Basil Blackwell, 129-138.

GTL, s/d., Plano de Pormenor de Salvaguarda e Reabilitação do Núcleo Histórico de Óbidos. Óbidos, Câmara Municipal, Gabinete Técnico Local, policopiado.

HERZFELD, Michael, 1991, A Place in History: Social and Monumental Time in a Cretan Town. Princeton, NJ, Princeton University Press.

HIRSCH, Eric, 1995, "Introduction: landscape: between place and space", em Eric Hirsch e Michael O'Hanlon (orgs.), The Anthropology of Landscape: Perspectives on Place and Space. Oxford, Clarendon Press, 1-30.

INE, 2001, Censos 2001: Recenseamento Geral da População, Resultados Definitivos. Lisboa, Instituto Nacional de Estatística.

INE, 2008, Anuário Estatístico da Região Centro 2007. Lisboa, Instituto Nacional de Estatística. 
INGOLD, Tim, 1993, "The temporality of the landscape”, World Archaeology, 25 (2): 152$-174$.

JACOBSEN, Jens, 2000, "Anti-tourist attitudes: Mediterranean charter tourism", Annals of Tourism Research, 27 (2): 284-300.

KIRSHENBLATT-GIMBLETT, Barbara, 1998, Destination Culture: Tourism, Museums and Heritage. Berkeley, University of California Press.

KÜCHLER, Susanne, 1993, "Landscape as memory: the mapping of process and its representation in a Melanesian society”, em Barbara Bender (org.), Landscape: Politics and Perspectives. Providence, Berg Publishers, 85-106.

LOW, Setha, e Denise LAWRENCE-ZÚÑIGA, 2003, "Locating culture", em Setha Low e Denise Lawrence-Zúñiga (orgs.), The Anthropology of Space and Place. Oxford, Blackwell Publishing, 1-47.

LOWENTHAL, David, 1985, The Past is a Foreign Country. Cambridge, Cambridge University Press.

MacCANNELL, Dean, 1976, The Tourist: A New Theory of the Leisure Class. Nova Iorque, Schocken.

McCRACKEN, Grant, 1988, Culture and Consumption: New Approaches to the Symbolic Character of Consumer Goods and Activities. Indianápolis, Indiana University Press.

MELO, Daniel, 2001, Salazarismo e Cultura Popular (1933-1958). Lisboa, Imprensa de Ciências Sociais.

MUNT, Ian, 1994, “The 'other' postmodern tourism: culture, travel and the new middle classes", Theory Culture Society, 11 (4): 101-123.

PERALTA, Elsa, 2010 “'Somos todos marítimos': uma etnografia das (in)visibilidades do poder na representação social do passado local em Ílhavo”, Etnográfica, 14 (3): 443-464.

PIRES, Ema Cláudia, 2003, O Baile do Turismo: Turismo e Propaganda no Estado Novo. Casal de Cambra, Caleidoscópio.

PRATS, Llorenç, 1997, Antropologia y Patrimonio. Barcelona, Editorial Ariel.

PRISTA, Marta, 2011 , Discursos sobre o Passado: Investimentos Patrimoniais nas Pousadas de Portugal. Lisboa, Faculdade de Ciências Sociais e Humanas da Universidade Nova de Lisboa, tese de doutoramento em antropologia.

SASSATELli, Roberta, 2007, Consumer Culture: History, Theory and Politics. Londres, Sage.

SILVA, Filipe Rocha da, 1998, “Óbidos: anos 60, anos 90”, em Benedita Pestana (org.), Linha do Oeste: Óbidos e Monumentos Artísticos Circundantes. Lisboa, Assírio \& Alvim, 59-75.

SILVA, Luís, 2007, "Sortelha e Monsaraz: estudo de caso de dois lugares turísticos no interior de Portugal”, Análise Social, XLII (184): 853-874.

SILVA, Luís, 2011, "Beneath the surface of the heritage enterprise: governmentality and cultural representation of rural architecture in Portugal”, Ethnologia Europaea, 41 (2): 39-53.

SMITH, Valene (org.), 1978, Hosts and Guests: The Anthropology of Tourism. Oxford, Basil Blackwell.

SMITH, Valene, e William EADINGTON (orgs.), 1992, Tourism Alternatives. Filadélfia, University of Pennsylvania Press.

SOBRAL, José Manuel, 2004, "O genuíno, o espúrio e a identidade local: um estudo de caso das políticas de património em meio rural”, Etnográfica, VIII (2): 243-271.

TIMOTHY, Dallen, e Stephen BOYD, 2003, Heritage Tourism. Essex, Pearson Education Limited. 
TOMÉ, Miguel, 2002, Património e Restauro em Portugal (1920-1995). Porto, FAUP Publicações.

TRIGO, Jorge, 2004. A Importância dos Caminhos-de-Ferro no Desenvolvimento da Região Oeste de 1880 a 2002. Lisboa, FLUL, tese de mestrado.

TRINDADE, João (org.), 2001, Memórias Históricas e Diferentes Apontamentos, acerca das Antiguidades de Óbidos: Desde o Ano 308 antes de Jesus Cristo até ao Presente, Tirados dos Historiadores Portugueses e Espanhóis e Manuscritos Originais dos Arquivos, de que Se Faz Menção Nestes Apontamentos. Óbidos, Câmara Municipal de Óbidos.

TUAN, Yi-Fu, 1974, Topophilia: A Study of Environmental Perception, Attitudes, and Values. Nova Iorque, Columbia University Press. 